\title{
SISTEM PENDUKUNG KEPUTUSAN SELEKSI PEMAIN BOLA MENGGUNAKAN METODE ANALYTICAL HIERARCHY PROCESS (AHP)
}

\author{
Asrianda, Rozzi Kesuma D, Rahmat Hidayat \\ Program Studi Teknik Informatika Fakultas Teknik \\ Universitas Malikussaleh \\ Jl. Batam Kampus Bukit Indah Gedung Teknik Informatika \\ rahmat@pajanlom.com ${ }^{1}$
}

\begin{abstract}
Abstrak
Abstrak - Setiap tim sepak bola mempunyai standar yang digunakan oleh pelatih dalam menentukan pemain yang sesuai dengan kriteria untuk dimasukkan ke dalam starting eleven. Terkadang pelatih bingung menentukan pemain terbaik yang dapat dimainkan. Tujuan penelitian ini adalah membuat sistem pendukung keputusan pemilihan starting eleven dan mengimplementasikan analytical hierarchy process ke dalam sistem. Penelitian ini menggunakan metode analytical hierarchy process. Proses dari metode tersebut adalah mendefinisikan masalah dan menentukan solusi, menentukan prioritas elemen, menentukan, mengukur konsistensi, menghitung indeks konsistensi, menghitung rasio konsistensi, dan memeriksa konsistensi hierarki. Sehingga sistem menghasilkan rekomendasi starting eleven sesuai standar yang digunakan oleh pelatih. Berdasarkan hasil percobaan kasus yang telah dilakukan, dapat diketahui bahwa hasil perhitungan dari sistem ini sama dengan hasil perhitungan yang dilakukan secara manual. Selanjutnya, perubahan nilai bobot setiap perbandingan kriteria mempengaruhi hasil akhir, sehingga rekomendasi starting eleven dapat berubah-ubah. Secara keseluruhan penelitian ini menghasilkan sistem pendukung keputusan pemilihan starting eleven dan berhasil mengimplementasikan analytical hierarchy process ke dalam sistem.
\end{abstract}

Kata Kunci : Sistem Pendukung Keputusan, Starting Eleven, Analytical Hierarchy Process 


\section{Pendahuluan}

Sepak bola adalah salah satu cabang olahraga yang paling diminati oleh sebagian besar penduduk di Indonesia. Banyak di antara para penggemar sepak bola mempunyai pendapat terhadap permainan sebuah tim sepak bola. Permainan tim juga ditentukan oleh pemain, pelatih dan strategi yang diterapkan dalam sebuah pertandingan.

Dalam perkembangannya sepak bola berevolusi menjadi sepak bola modern yang sangat mementingkan sebuah strategi dan komposisi pemain yang paling sesuai dengan situasi dan kondisi yang sedang terjadi pada saat itu juga. Pemain yang dipilih oleh pelatih menentukan permainan tim. Pemain yang dipilih pelatih terkadang tidak sesuai antara kemampuan yang dimiliki pemain dengan standar yang diinginkan oleh pelatih. Starting eleven merupakan sebelas pemain utama yang telah dipilih oleh pelatih dari awal pertandingan (Kuper, 2009). Sebelas pemain yang terdiri dari penjaga gawang, pemain belakang, pemain tengah dan pemain depan.

Oleh karena permasalahan ini akan dibangun sistem pendukung keputusan yang mempermudah seorang user atau dalam hal ini adalah pelatih dalam memilih pemain. Pemain yang siap untuk dimainkan dari awal pertandingan diperoleh dari perbandingan antara kriteria-kriteria yang digunakan di dalam sistem. Sehingga pelatih dapat memilih pemain-pemain yang sesuai dengan perbandingan kriteria yang telah ditentukan oleh pelatih.

Berdasarkan permasalahan tersebut, diperlukan sistem yang dapat mendukung keputusan dalam pemilihan starting eleven agar pelatih atau manajer tim dapat menentukan pemain dengan tepat sesuai dengan standar pemain yang diinginkan. Metode yang digunakan dalam pengambilan keputusan pemilihan starting eleven ini dengan menggunakan metode Analytical Hierarchy Process (AHP) 


\section{Metode Penelitian}

2.1 Kriteria Seleksi Pemain

Adapun kriteria yang dibutuhkan dalam menyeleksi pemain bola di SSB Bireuen dapat dilihat pada table 2.1 berikut :

\begin{tabular}{|c|c|c|}
\hline No & kriteria & subkriteria \\
\hline 1 & \multirow{3}{*}{ Fisik } & Kelincahan \\
\cline { 3 - 3 } & & Keseimbangan \\
\cline { 3 - 3 } & & Kecepatan Reaksi \\
\hline \multirow{2}{*}{2} & \multirow{2}{*}{ Teknik } & Passing bawah \\
\cline { 3 - 3 } & & Passing atas \\
\cline { 3 - 3 } & & Dribbling \\
\cline { 3 - 3 } & & Shooting \\
\cline { 3 - 3 } & & Heading \\
\hline 3 & Kognitif & Tackling \\
\hline
\end{tabular}

\subsection{Skema Sistem}

Adapun skema dalam penelitian ini dapat dilihat pada gambar 3.1 berikut :

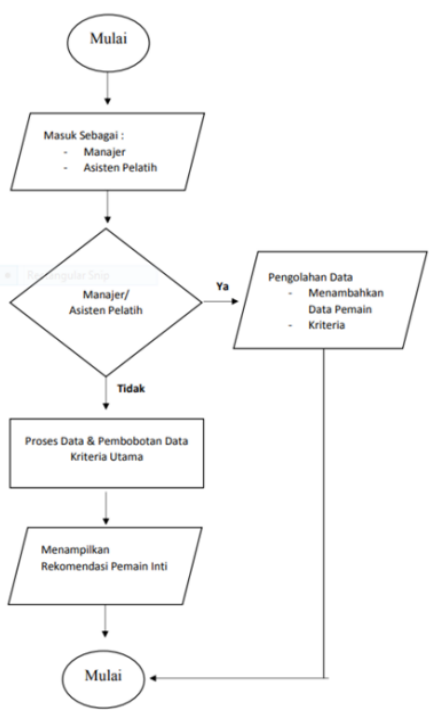

Gambar 1. Flowchart 


\section{Analisa dan Pembahasan}

\subsection{Analisa Sistem}

Sistem pendukung keputusan ini dibangun berbasis web dengan menggunakan algoritma AHP (analytic hierarchy process) untuk menentukan pemain yang terpilih berdasarkan kriteria yang sudah ditetapkan. Langkah awal yang perlu dilakukan dalam membangun sistem pendukung keputusan ini adalah mendapatkan data seleksi dari tim sepakbola SSB Bireuen, data yang diperlukan diantaranya data kriteria seleksi dan bobot kepentingan dari setiap kriteria yang ditentukan.

\subsubsection{Analisa Input}

Agar proses pemilihan pemain dapat di proses menggunakan algoritma AHP, terlebih dahulu admin/manager tim menentukan kriteria dan sub kriteria yang dibutuhkan. Selanjutnya dengan memasukkan data pemain dan nilai setiap pemain untuk masingmasing kriteria dan sub kriteria.

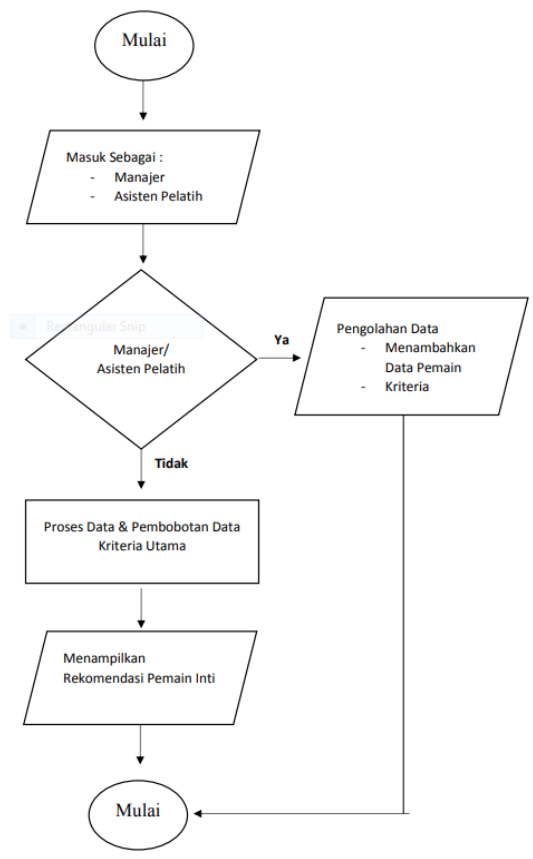

Gambar 2. Flowchart Proses Input 


\subsubsection{Analisa Proses}

Nilai kriteria dan sub kriteria untuk setiap pemain yang sudah di-input akan diproses berdasarkan algoritma AHP sehingga mendapatkan hasil yang seleksi pemain berdasarkan nilai yang di-input

\subsubsection{Analisis Perhitungan Metode AHP}

Berdasarkan hasil pengumpulan data, dapat diketahui bahwa terdapat tiga kriteria dasar yang saat ini digunakan dalam menetukan pemilihan starting eleven yaitu fisik, teknik, dan kognitif. Struktur hirarki permasalahan yang ada dalam sistem pemilihan starting eleven yang dibangun dapat dilihat pada gambar 3 .

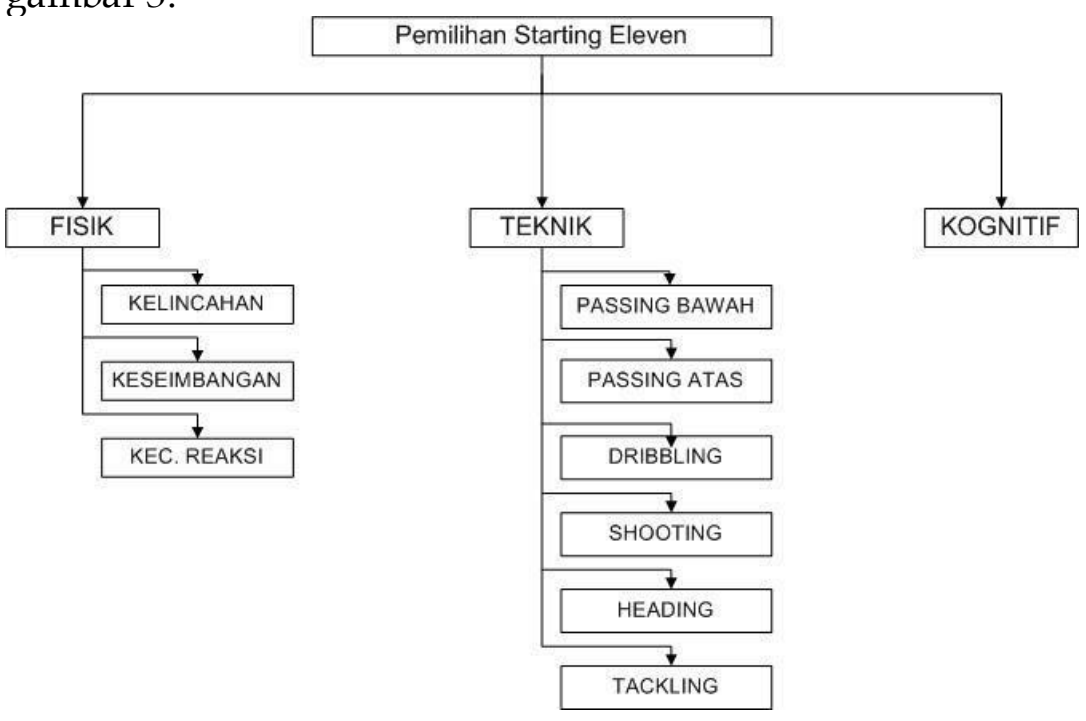

\section{Gambar 3. Hirarki Permasalahan}

Tahapan - tahapan yang harus dilakukan dalam tahap ini antara lain adalah:

1. Menentukan prioritas kriteria

Langkah yang harus dilakukan dalam menentukan prioritas kriteria adalah sebagai berikut:

a. Membuat matriks perbandingan berpasangan 
Sistem Pendukung Keputusan Seleksi Pemain Bola Menggunakan Metode Analytical Hierarchy Process (AHP)

Tabel 3.1 Matriks Perbandingan Berpasangan

\begin{tabular}{|l|c|c|c|}
\hline & Teknik & Fisik & Kognitif \\
\hline Teknik & 1 & 1 & 3 \\
\hline Fisik & 1 & 1 & 2 \\
\hline Kognitif & 0.333 & 0.5 & 1 \\
\hline Jumlah & 2.333 & 2.5 & 6 \\
\hline
\end{tabular}

Angka 1 pada kolom teknik baris teknik menggambarkan tingkat kepentingan yang sama antara teknik dengan teknik. Sedangkan angka 3 pada kolom kognitif baris teknik menunjukkan kognitif sedikit lebih penting dibandingkan teknik. Angka 0,333 pada kolom teknik baris kognitif merupakan hasil perhitungan 1/nilai pada kolom kognitif baris teknik. Angka angka yang lain diperoleh dengan cara yang sama.

b. Membuat matriks nilai kriteria

Matriks ini diperoleh dengan rumus berikut:

Nilai baris kolom baru $=$ Nilai baris-kolom lama/jumlah masing-masing kolom lama.

Hasil perhitungan dapat dilihat pada tabel3.2

Tabel 3.2 Matriks Nilai Kriteria

\begin{tabular}{|l|c|c|c|c|c|}
\hline & Teknik & Fisik & Kognitif & Jumlah & Prioritas \\
\hline Teknik & 0,429 & 0,4 & 0,5 & 1,329 & 0,443 \\
\hline Fisik & 0,429 & 0,4 & 0,333 & 1,162 & 0,387 \\
\hline Kognitif & 0,143 & 0,3 & 0,167 & 0,51 & 0,17 \\
\hline
\end{tabular}

Nilai 0,353 pada kolom teknik baris teknik Tabel 4.2 diperoleh dari nilai kolom teknik baris teknik Tabel 4.1 dibagi jumlah kolom teknik Tabel 3.1.

Nilai kolom jumlah pada Tabel 4.2 diperoleh dari penjumlahan pada setiap barisnya. Untuk baris pertama, nilai 1,329 merupakan hasil penjumlahan dari 0,429+0,4+0,5.

Nilai pada kolom prioritas diperoleh dari nilai pada kolom jumlah dibagi dengan jumlah kriteria. 
c. Membuat matriks penjumlahan setiap baris

Matriks ini dibuat dengan mengalikan nilai prioritas pada Tabel 3.2 dengan matriks perbandingan berpasangan (Tabel 3.1). Hasil perhitungan disajikan dalam Tabel 3.3.

Tabel 3.3 Matriks Penjumlahan Setiap Baris

\begin{tabular}{|l|c|c|c|c|}
\hline Focus & Teknik & Fisik & Kognitif & Jumlah \\
\hline Teknik & 0,443 & 0,387 & 0,51 & 1.34 \\
\hline Fisik & 0,443 & 0,387 & 0,34 & 1.17 \\
\hline Kognitif & 0,148 & 0,194 & 0,17 & 0.512 \\
\hline
\end{tabular}

Nilai 0,351 pada kolom teknik baris teknik Tabel 3.3 diperoleh dari prioritas baris teknik pada Tabel $3.2(0,443)$ dikalikan dengan nilai baris teknik kolom teknik pada Tabel 3.1.

Nilai 0,148 pada baris kognitif kolom teknik tabel 3.3 diperoleh dari prioritas baris kognitif pada Tabel $3.2(0,17)$ dikalikan nilai baris kognitif kolom teknik pada Tabel $4.1(0,333)$.

Kolom jumlah pada Tabel 4.3 diperoleh dengan menjumlahkan nilai pada masing-masing baris pada tabel tersebut. Misalnya, nilai 1.17 pada kolom jumlah merupakan hasil penjumlahan dari $0,443+0,387+0,34$.

d. Perhitungan rasio konsistensi

Perhitungan ini digunakan untuk memastikan bahwa nilai rasio konsistensi $(\mathrm{CR})<=0,1$. Jika ternyata nilai $\mathrm{CR}$ lebih besar dari 0,1, maka matriks perbandingan berpasangan harus diperbaiki.

Untuk menghitung rasio konsistensi, dibuat tabel seperti terlihat dalam 3.4.

\section{Kesimpulan dan Saran}

\subsection{Kesimpulan}

Berdasarkan hasil pengujian yang telah dilakukan penulis pada sistem pendukung keputusan pemilihan di SSB Brata Kota Juang, Bireuen, maka dapat diambil beberapa keputusan sebagai berikut: 
1. Penelitian berhasil membangun sistem pendukung keputusan menggunakan metode Analytical Hierarchy Process.

2. Penelitian berhasil mengimplementasikan sistem pendukung keputusan untuk menentukan pemain pada cabang olahraga sepak bola di SSB Brata Kota Juang, Bireuen.

\subsection{Saran}

Penelitian yang dilakukan tidak terlepas dari kekurangan dan kelemahan. Oleh karena itu, untuk kebaikan pengembangan sistem lebih lanjut, maka perlu diperhatikan beberapa hal diantaranya :

1. Sistem yang dibangun diharapkan dapat dijadikan sebagai bahan dalam pengembangan dan penelitian lebih lanjut sehingga mampu menghasilkan sistem baru yang lebih bermanfaat.

2. Menambahkan kriteria-kriteria baru yang sesuai dengan perkembangan sepak bola di Indonesia khususnya di SSB SSB Brata Kota Juang, Bireuen.

3. Besar harapan penulis untuk yang melanjutkan penelitian ini untuk menguji tingkat kompleksitas algoritma yang digunakan pada pengujian aplikasi pendukung keputusan dalam pemilihan pemain bola.

4. Antarmuka dari sistem yang dibangun masih tampak sederhana sehingga dapat dikembangkan lebih menarik untuk kenyamanan pengguna.

\section{Daftar Pustaka}

K. Kusrini, Konsep dan Aplikasi Sistem Pendukung Keputusan. Yogyakarta: Penerbit Andi, 2007.

Ari, R. (2011). Sistem Pendukung Keputusan Penentuan Posisi Pemain Pada Olahraga Bola Voli. Yogyakarta : Universitas Ahmad Dahlan. 
Ulum, M. (2012). Sistem Pendukung Keputusan Penyetujuan Penerbitan Buku dengan Metode Analytical Hierarchy Process (Studi Kasus: PT. Galangpress Media Utama Baciron Yogyakarta). Yogyakarta : UIN Sunan Kalijaga.

Sinaga, Bosker., 2014 "Implementasi Sistem Pendukung Keputusan Siswa Berprestasi Menggunakan Metode Analytic Hierarchy Process (AHP)", Jurnal Mantik Penusa Vol. 16 no 2

S. P. K. Utomo, and P. Kurniawan, “Sistem Penunjang Keputusan dalam Pemilihan Pemain Untuk Posisi Tertentu pada Sepakbola, Semnasteknomedia Online, vol. 4, no. 1, Februari 2016. 